\title{
REVITALISASI GLODOK SEBAGAI TEMPAT BERSOSIALISASI KOMUNITAS MASYARAKAT TIONGHOA
}

\author{
Sharen $^{1)}$, Budi Adelar Sukada ${ }^{2)}$ \\ 1)Program Studi S1 Arsitektur, Fakultas Teknik, Universitas Tarumanagara,sharenw01@gmail.com \\ 2)Program Studi S1 Arsitektur, Fakultas Teknik, Universitas Tarumanagara,budisukada@yahoo.com
}

\begin{abstract}
Abstrak
Kawasan Glodok Pancoran merupakan salah satu kawasan di DKI Jakarta yang memiliki nilai ekonomi dan budaya yang tinggi. Kawasan Glodok telah eksis sejak jaman Belanda menjajah Indonesia sampai saat ini. Glodok Pancoran yang dikenal sebagai pusat perdagangan khas Tionghoa dan Betawi, mulai dari kuliner, obat-obatan, dan pernak-pernik mempunyai potensi yang besar sebagai kawasan wisata seni dan budaya di Jakarta Barat. Studi ini menjelaskan tentang perencanaan perkembangan kawasan Glodok untuk meningkatkan citra kawasan dan memaksimalkan potensi wisata seni dan budaya. Pola kehidupan berdagang dan aktivitas sehari-hari menjadi dasar untuk perancangan desain dengan tujuan untuk meningkatkan wisatawan kota Jakarta maupun mancanegara. Analisis data dilakukan dengan menggunakan teori yaitu analisis berdasarkan aspek lingkungan, aspek manusia dan aspek bangunan yang dipadu dengan teori lainnya. Hasil yang akan dicapai adalah konsep desain kawasan Glodok Pancoran sebagai kawasan wisata seni dan budaya di kelurahan Pinangsia, Jakarta Barat dengan memperhatikan pengalaman wisatawan di dalam kawasan.
\end{abstract}

\section{Kata kunci: Glodok Pancoran; Pecinan; Wisata Seni dan Budaya}

\begin{abstract}
Glodok Pancoran is one of the areas in DKI Jakarta that has high economic and cultural values in the Netherlands, colonizing Indonesia until now. Glodok Pancoran, known as the center of typical Chinese and Betawi trade, ranging from culinary, medicine, and trinkets has great potential as an area of art and cultural tourism in West Jakarta. This research describes the development planning of the Glodok Pancoran to improve the image of the region and maximize the potential of the arts and cultural tourism. The pattern of trading life and daily activities become the basis for designing the design with the aim to increase Jakarta or foreign tourists. Data analysis was performed using theory, namely analysis based on environmental aspects, human aspects and building aspects combined with other theories. The result that will be received is the design concept of the Glodok Pancoran area as an art and cultural tourism area in West Jakarta by taking into account tourism experiences within the area. The result that will be achieved is the design concept Glodok Pancoran area as an art and cultural tourism area in Pinangsia village, West Jakarta by taking into account the experience of tourists in the area.
\end{abstract}

Keywords: Art and Culture Tourism; Glodok Pancoran; Pecinan

\section{PENDAHULUAN}

\section{Latar Belakang}

Glodok Pancoran merupakan salah satu wilayah di DKI Jakarta dengan luas $0,38 \mathrm{Km}^{2}$ yang merupakan kawasan pusat perdagangan, perkantoran, serta hiburan. Arus lalu lintas pada kawasan tersebut cukup padat sepanjang hari terutama pada siang dan sore hari. Sehingga membuat orang cukup enggan untuk melintasi ke daerah tersebut. Seiring dengan berjalannya 
waktu, budaya Tionghoa di Glodok Pancoran terancam menghilang karena bukti-bukti sejarah yang ada sejak dahulu kini tidak dilestarikan lagi. Generasi muda maupun tua tidak lagi memilki rasa kepedulian untuk mau memahami budaya yang ada di Glodok Pancoran. Glodok Pancoran hanya dianggap sebagai tempat berdagang, kumuh, banyak pedagang kaki lima, macet, tidak tertata, dan hanya menganggap sebagai kawasan yang tidak memiliki nilai bersejarah, seperti kawasan pemukiman warga di Jakarta pada umumnya. Dengan adanya pengembangan wisata disuatu kawasan maka akan memberikan keuntungan bagi lingkungan sekitarnya. Selain itu, pengembangan wisata ini juga merupakan salah satu upaya untuk meningkatkan kesadaran masyarakat untuk dapat menjaga, melestarikan, serta menambah wawasan. Dengan adanya upaya pelestarian ini, sejarah dan budaya akan tetap hidup dan dapat dinikmati oleh generasigenerasi mendatang.

\section{Rumusan Masalah}

Dari latar belakang tersebut, terdapat beberapa masalah yang ditemukan dan dapat menjadi bahan penelitian antara lain:

a. Kawasan Glodok Pancoran yang tidak tertata rapih dan macet.

b. Tidak adanya rasa kepedulian warga untuk memahami dan melestarikan kebudayaan yang ada di Glodok Pancoran.

c. Pandangan masyarakat terhadap kawasan Glodok Pancoran hanya sebagai kawasan perekonomian dan tidak memiliki nilai bersejarah.

\section{Tujuan}

a. Menghilangkan rasa jenuh, dan penat karena kegiatan yang padat sehari-hari.

b. Untuk memperkaya pengetahuan masyarakat akan kebudayaan daerah setempat. yang semakin punah oleh keadaan jaman yang semakin berkembang.

c. Untuk menciptakan sebuah ruang publik yang edukatif.

d. Meningkatkan peranan dalam perekonomian Jakarta.

e. Menciptakan ruang terbuka baru sehingga kepadatan bangunan dapat berkurang.

f. Memberikan peluang kepada wisatawan untuk menciptakan karyanya sendiri.

\section{KAJIAN LITERATUR}

\section{Ruang Publik}

Ruang publik merupakan ruangan yang berfungsi sebagai tempat untuk menampung aktivitas masyarakat, baik secara individu maupun secara kelompok, dimana bentuk ruang publik ini tergantung pada susunan massa bangunan (Rustam Hakim, 1987). Menurut Carr (1992), tipologi ruang publik yaitu bergantung pada karakter kegiatannya, lokasi dan proses pembentuknya. Carr dkk membagi tipologi ruang publik yaitu: jalan, taman bermain, jalur hijau, perbelanjaan dalam ruang, ruang spontan dalam lingkungan hunian, ruang terbuka komunitas, square dan plaza, pasar, tepi air.

\section{Tempat Ketiga}

Manusia sebagai mahluk sosial tidak dapat hidup secara individu dalam melakukan aktivitas sehari-hari. Oleh karena itu, manusia membutuhkan first place sebagai tempat tinggal dan second place sebagai tempat kerja atau tempat belajar. Third Place menurut Oldenburg (1997) dalam buku The Great Good Place merupakan ruang yang memungkinkan bagi manusia untuk melakukan interaksi dan berkumpul bersama keluarga, saudara dan teman secara berkala. Dapat pula sebagai tempat untuk masyarakat yang ingin berelaksasi, berekspresi, bertukar pikiran maupun bersosialisasi agar perasaan stress, kesepian, terasingkan dapat disalurkan secara lebih positif serta mendapatkan ketenangan setiap individu. 


\section{Revitalisasi}

Revitalisasi adalah cara menghidupkan kembali suatu kawasan kota yang telah menurun melalui intervensi-intervensi fisik maupun non-fisik untuk mengakomodasi kebutuhan dan tantangan baru (Sri-Edi Swasono, 2002).

\section{Sejarah Orang Tionghoa di Indonesia}

Orang Tionghoa yang datang ke Wilayah Nusantara datang secara bertahap. Sebagian berasal dari provinsi-provinsi di Fujian dan Kwangtung. Mereka memiliki kebudayaan yang berbeda satu sama lainnya.

\section{Orang Hakka di Indonesia}

Di Indonesia orang Hakka banyak terdapat di Aceh, Bangka-Belitung, Jawa, serta Kalimantan Barat serta tersebar merata di seluruh dunia. Orang Hakka memiliki bahasa sendiri yaitu bahasa Khek. Dikenal sebagai orang-orang yang sangat rajin dan ulet bekerja. Julukan ini berasal dari kisah pada jaman dahulu dimana mereka hidup berpindah-pindah dari satu tempat ke tempat lain. Oleh karena itu, mereka dinamakan keluarga pendatang. Selain itu, mereka juga merupakan pedagang yang handal. Tidak mengenal perbedaan gender, wanita dan laki-laki sama-sama harus bekerja.

\section{Asal Usul Nama Glodok}

Nama Glodok berasal dari kata grojok, karena pada zaman Belanda, terdapat sebuah pancuran besar jika hujan, keluar air dengan bunyi grojok grojok grojok. Oleh warga sekitar, bunyi air tersebut diucapkan dengan kata glodok sehingga lama kelamaan tempat tersebut disebut Glodok. Glodok diambil dari sebuah jembatan yang membentang di atas Kali Besar (Ciliwung) di kawasan itu. Namanya adalah jembatan kali Glodok. Sebab, pada ujung jembatan tersebut terdapat tangga yang menempel pada tepi kali yang biasa digunakan penduduk setempat untuk mandi dan mencuci pakaian. Dalam bahasa Sunda, tangga itu disebut sebagai glodok, sama seperti sebutan untuk tangga rumah. (Asal-Usul Djakarta Tempo Doeloe,2012).

\section{METODE}

Pendekatan penelitian ini berlangsung secara teoritis dan secara kualitatif yaitu mengkaji data berdasarkan fenomena terkait permasalahan dan melalui studi literatur dengan membaca buku, artikel, jurnal, dan studi preseden terkait dengan objek penelitian (wawancara dan kuisioner kepada narasumber). Sedangkan data kuantitatif terkait objek penelitian diperoleh melalui pengamatan langsung.

\section{Pengumpulan Data}

Sumber data dan informasi untuk mendukung proposal ini didapat melalui:

a. Observasi (pengamatan): suatu kegiatan yang dilakukan dengan mengamati dan mencatat secara sistematis terhadap gejala atau fenomena. Dengan tujuan mendapatkan data atau informasi-informasi yang berkaitan dengan budaya setempat.

b. Penyebaran angket / kuesioner / wawancara: suatu kegiatan yang dilakukan dengan cara bertanya langsung kepada pihak yang terlibat (sumber). Wawancara ini dilakukan pada warga sekitar yang tinggal di Glodok sejak lama dan para pedagang keliling pada kawasan Glodok yang menetap lama. Selain dengan wawancara, untuk mendapatkan data secara langsung juga dapat dilakukan dengan cara dokumentasi.

c. Dokumentasi, metode yang digunakan untuk mencari data yang diperlukan berdasarkan peristiwa yang ada.

d. Studi preseden, yaitu membedah rancangan-rancangan nyata atau telah terbangun yang memiliki kemiripan program pada proyek yang diajukan.

e. Studi literatur terkait teori, data, penelaahan, dan sejarah. 


\section{Data Primer}

Data primer merupakan sumber data yang diperoleh langsung dari sumber asli. Data primer dapat berupa opini subjek (orang) secara individual / kelompok, hasil observasi terhadap suatu benda (fisik), kejadian atau kegiatan, dan hasil pengujian. Metode yang digunakan yaitu metode survey dan metode observasi. Data primer diperoleh melalui metode survey lapangan dan penyusunan kuisioner dengan pengambilan sampling sebanyak 90 orang dan menghitung akumulasi hasil dari perhitungan kuisioner tersebut.

\section{Data Sekunder}

Data sekunder merupakan sumber data penelitian yang diperoleh peneliti secara tidak langsung diperoleh dari pihak lain. Data sekunder diperoleh melalui beberapa media yang memberikan informasi terkait wisata budaya pada kelurahan Pinangsia.

\section{DISKUSI DAN HASIL}

\section{Analisis Lokasi}

Tabel 1. Tabel Identifikasi Kawasan

\begin{tabular}{|c|c|c|}
\hline Data & Analisis & Sintesis \\
\hline $\begin{array}{l}\text { - Kurangnya ruang } \\
\text { terbuka hijau sebagai } \\
\text { tempat wisata. }\end{array}$ & $\begin{array}{l}\text { - Membutuhkan RTH sebagai } \\
\text { sarana untuk mengurangi } \\
\text { polusi udara dan dapat } \\
\text { menyejukkan area tersebut. }\end{array}$ & $\begin{array}{l}\text { - Membuat area taman untuk } \\
\text { mengurangi polusi udara. }\end{array}$ \\
\hline $\begin{array}{l}\text { - Banyak menggunakan } \\
\text { kendaraan pribadi. } \\
\text { - Kurangnya pejalan kaki } \\
\text { dan sempitnya jalur } \\
\text { pedestrian. }\end{array}$ & $\begin{array}{l}\text { - Mengurangi penggunaan } \\
\text { kendaraan pribadi. } \\
\text { - Memaksimalkan fungsi } \\
\text { jalan pedestrian. }\end{array}$ & $\begin{array}{l}\text { - Pedestrian diperlebar dan } \\
\text { diperbaiki, memperjelas jalur } \\
\text { pejalan kaki tersebut. } \\
\text { - Membuat jalur sepeda dengan } \\
\text { adanya pemasangan lampu } \\
\text { penerangan jalan. }\end{array}$ \\
\hline $\begin{array}{l}\text { - Tidak adanya } \\
\text { wadah/tempat untuk } \\
\text { melestarikan budaya } \\
\text { sekitar Glodok. }\end{array}$ & $\begin{array}{l}\text { - Membutuhkan wadah/ } \\
\text { tempat sebagai sarana } \\
\text { pengembangan budaya dan } \\
\text { kreatifitas warga setempat. }\end{array}$ & $\begin{array}{l}\text { - Membuat wadah/tempat untuk } \\
\text { berkumpulnya warga sekitar } \\
\text { sehingga dapat melatih kekreatifan } \\
\text { dalam diri masing-masing. }\end{array}$ \\
\hline
\end{tabular}

Tapak terpilih memiliki data sebagai berikut:

a. Tapak berlokasi di Glodok Pancoran (JI. Pintu Besar Selatan I).

b. Tapak berada pada Sub Zona Rumah Besar KDB sedang (2-4 lantai).

c. Luas Tapak: $2.600 \mathrm{~m}^{2}$

d. Persyaratan pembangunan di tapak, antara lain:

e. KDB 55\%, KLB: 3, KTB: 55, KB:8, KDH: 30\%, GSB: $3 \mathrm{~m}$

f. Tapak bersebelahan dengan rumah toko dan apartemen 20 lantai, serta dekat dengan seni lukis mural yang berada di Kota Tua Jakarta.

g. Transportasi terdekat, yaitu terdapat stasiun kereta api Kota (berjarak kurang lebih $200 \mathrm{~m}$ ) dan halte bus TransJakarta Kota (berjarak kurang lebih $120 \mathrm{~m}$ ).

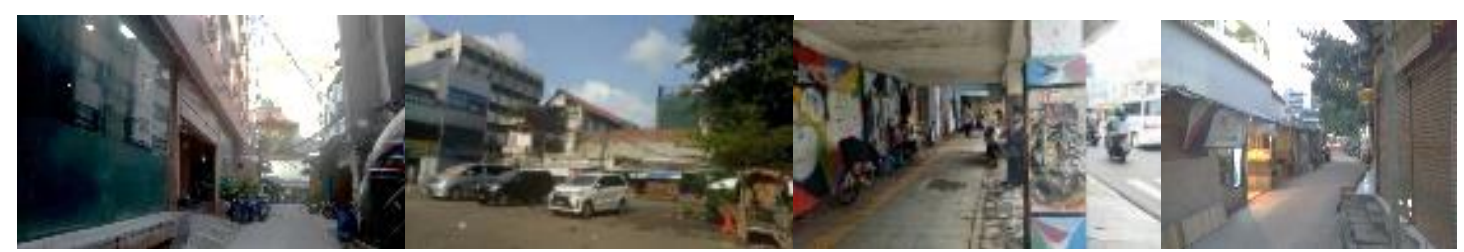

Gambar 1. Foto Suasana Tapak

Sumber: Penulis, 2020 


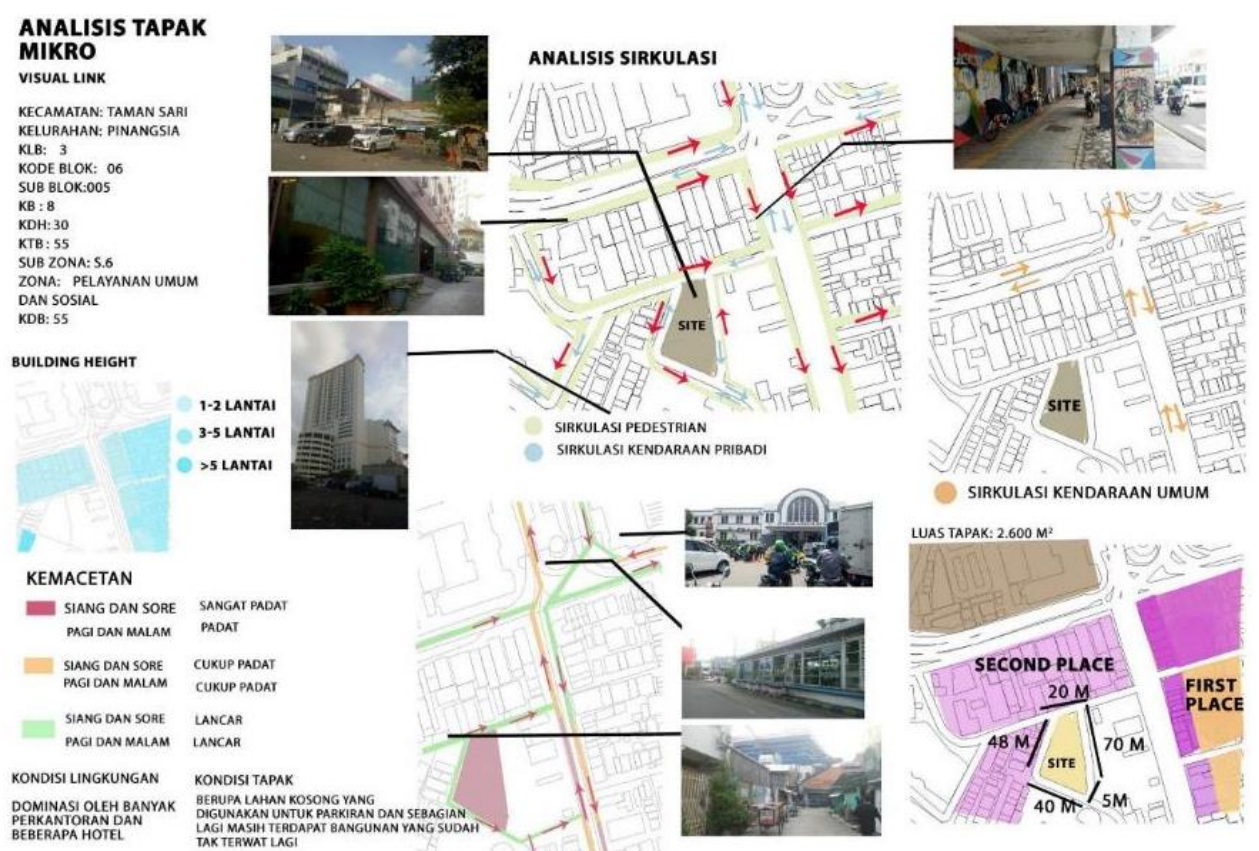

Gambar 2. Analisis Tapak Sumber: Penulis, 2020

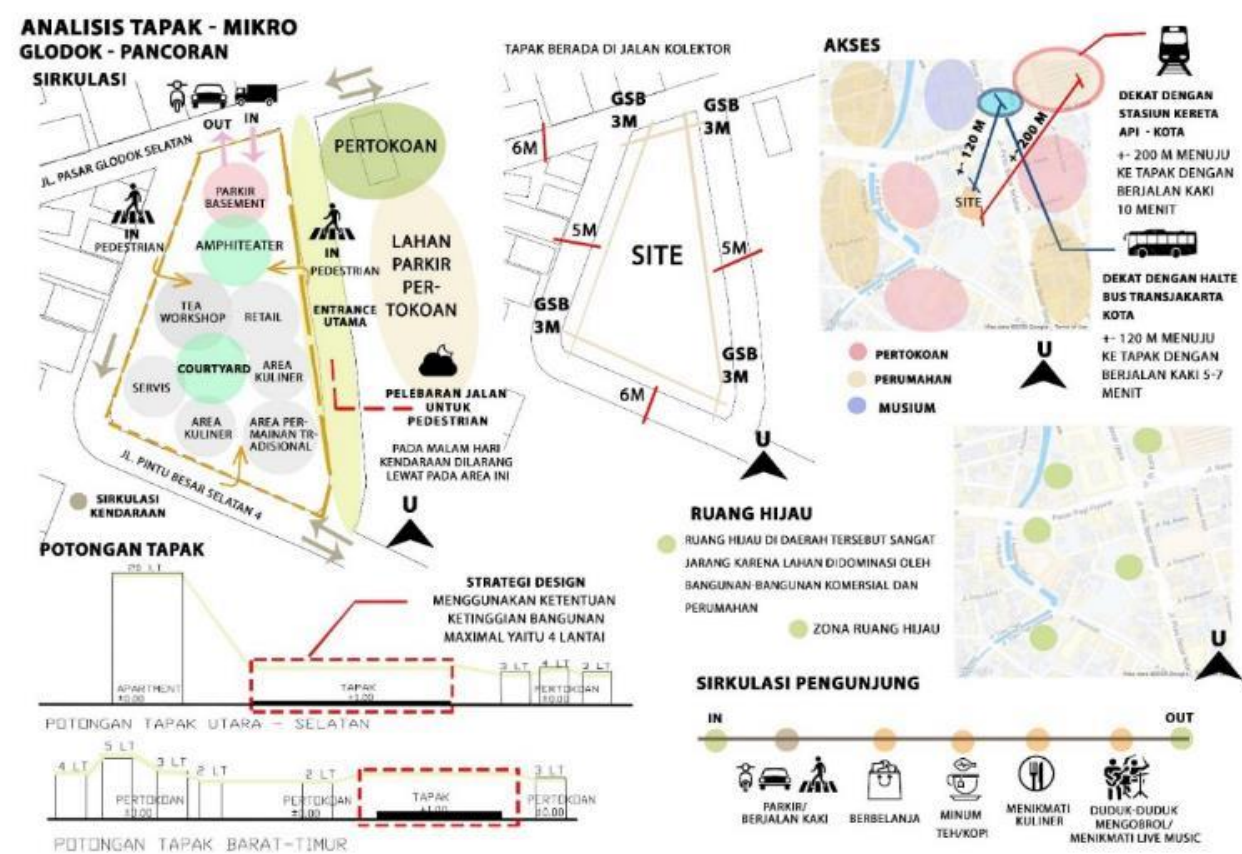

Gambar 3. Analisis Tapak

Sumber: Penulis, 2020

\section{Konsep Tata Ruang}

Tipologi bangunan bersifat rekreasi dan edukatif dengan konteks tradisional (eksterior) dan modern (interior). Berdasarkan hal tersebut maka dibentuklah konsep tata ruang sebagai berikut: bangunan yang didalamnya terdapat pelestarian budaya setempat yang terdapat sarana rekreasi hiburan seperti taman, live music dan area skateboard. Dengan adanya fasilitas berupa informasi wisata yang terdapat di sekitar kawasan Glodok. Sehingga dapat menjadikan kawasan Glodok menjadi suatu kawasan yang kreatif dan inovatif. 


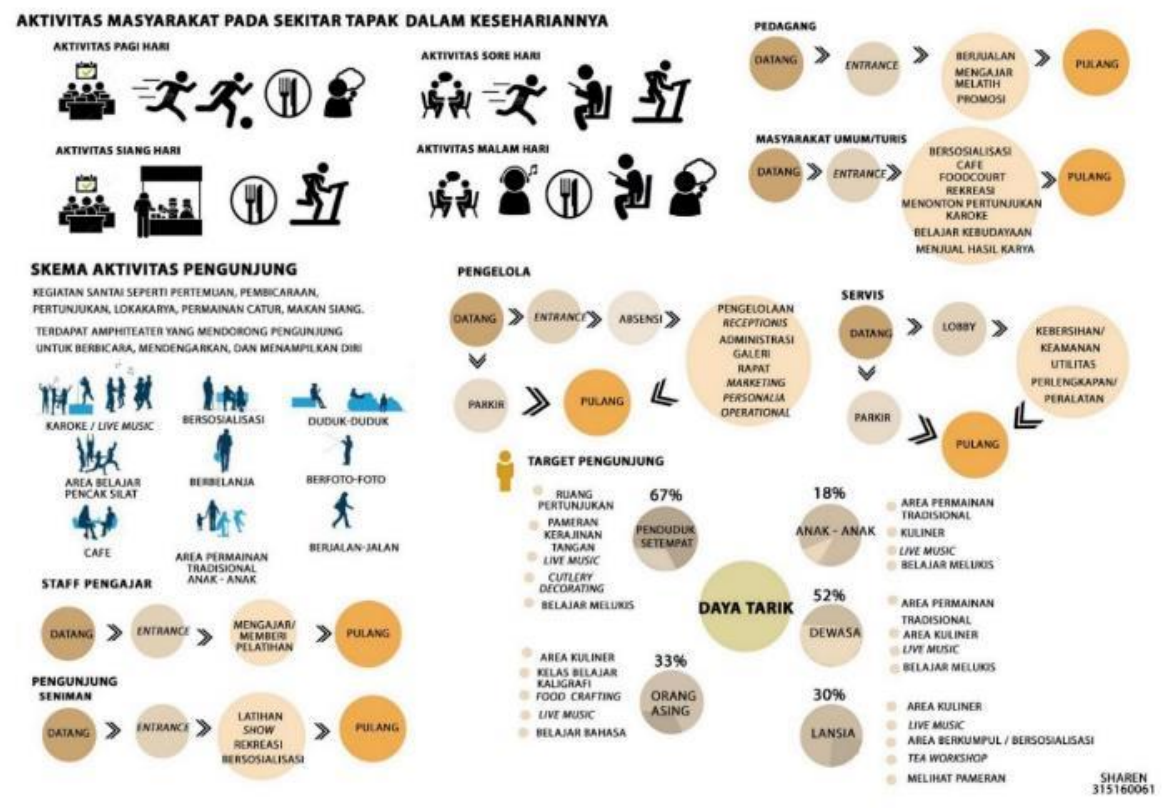

Gambar 4. Identifikasi Pengguna

Sumber: Penulis, 2020

\section{Identifikasi Pengguna}

Penduduk setempat (67\%) dapat melakukan kegiatan karoke/live music, berbelanja, belajar melukis, makan siang, permainan catur, dan lain sebagainya. Turis asing (33\%) dapat melakukan kegiatan belajar kaligrafi, kuliner, live music, berfoto, berbelanja serta belajar bahasa. Dengan target untuk anak-anak (18\%) dimana mereka dapat bermain permainan tradisional, melukis, berbelanja dan kuliner, sedangkan dewasa (52\%) mereka dapat berdiskusi, kuliner, live music, belajar menari tarian tradisional, belajar melukis dan lain sebagainya, lalu manula (30\%) dimana mereka dapat melakukan rekreasi manula seperti olahraga chikung, pemeriksaan kesehatan (sinshe), mengobrol, kuliner , dan lain sebagainya.

\section{Proses Gubahan Massa}

\begin{tabular}{lll}
$\begin{array}{l}\text { 1. Bentuk lingkaran memiliki } \\
\text { kemampuan statis yang } \\
\text { hebat yang menunjukan } \\
\text { bahwa kulit lingkaran lebih } \\
\text { stabil serta memberikan } \\
\text { kesan open/welcome } \\
\text { kepada semua orang. }\end{array}$ & $\begin{array}{l}\text { 2. Bangunan dipotong } \\
\text { sebagai sirkulasiudara alar } \\
\text { serta dapat memasukan } \\
\text { cahaya alami kedalam } \\
\text { bangunan sehingga dapat } \\
\text { hemat energi. Selain itu, } \\
\text { terdapat inner courtyard } \\
\text { sebagai tempat untuk } \\
\text { berkumpul/bersosialisasi. }\end{array}$ & $\begin{array}{l}\text { 3. Penambahanan plaza, area live bermain } \\
\text { terbuka public untuk }\end{array}$ \\
\hline bersosialisasi.
\end{tabular}

Gambar 5. Proses Gubahan Massa

Sumber: Penulis, 2020 


\section{Zoning Ruangan}

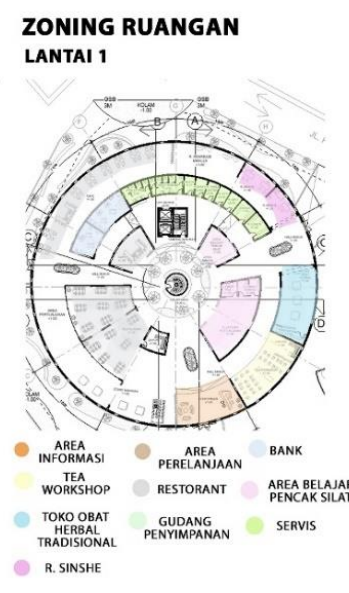

ZONING SERVIS BASEMENT

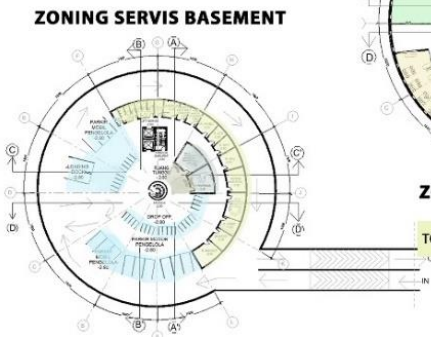

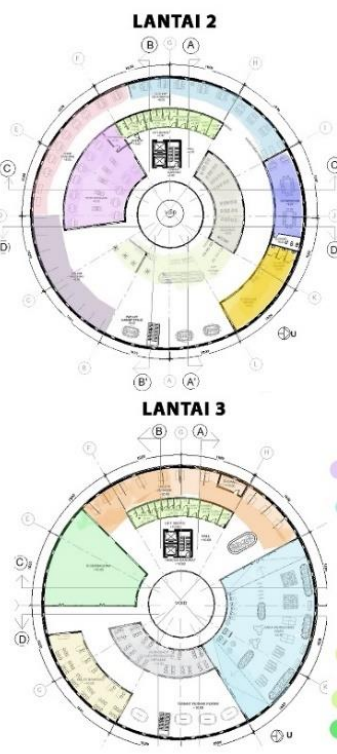

ZONING SERVIS BASEMENT
T.BELANAR

KALGRAFI
WORKSHOP
CHOKAYG

DECORATING

Perpustakan

AREA
PERELANJAAN

FOOD

CRAFTIN

SERVIS

ART
MARKER

- galeri kaligrafi

GUDANG PENYIMPANAN

PROGRAM UTAMA

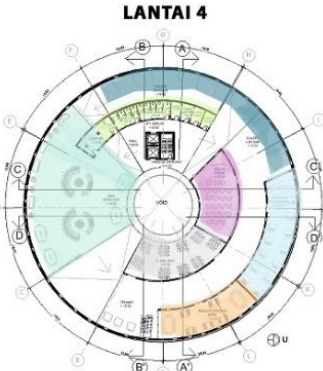

bar ROOFTOP GALERI LUKISAN

R. MELUKIS BRAINSTORMING AREA

PAINTING MOVIE ROOM

SERVIS

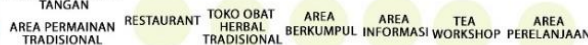

KERAMIK
WORSSHOP
PROGRAM PENDUKUNG

GALERI

penYimpanan

KELAS BAHASA

SERVIS

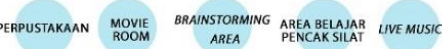

FOOD
CRAFTING WERAMIK MARSHOP MARESPACE AREA PERMANAN
TRADISIONAL

KANTOR PENGELOLA

R. PIMPINAN R. RRSIP PEATAT
PENGLLA R.KARYAWAN

TOILET - PARKIR $=$ GUDANG $=$ PANEL INDUK $\longrightarrow$ R. TUNGGU SUPIR $=$ R.KARYAWAN

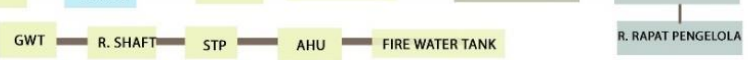

Gambar 6. Zoning Ruangan

Sumber: Penulis, 2020

\section{Konsep Perancangan}

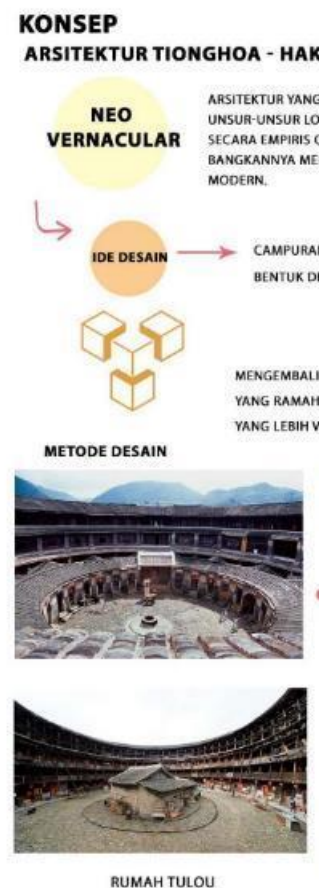

KONSEP

ARSITEKTUR YANG BERTUJUAN MELESTARIKAN UNSUA-UNSUR LOKAL YANG TELAH TERBENTUK

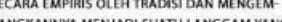

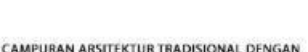
UTUK DESAIN YANG LEBIH MODERN.

ENGEMBALIKAN BENTUK-BENTUK TRADISIONAL EBIH VERTIKAL

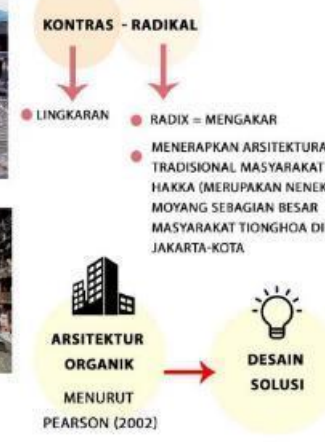

PLACEMAKING METHOD
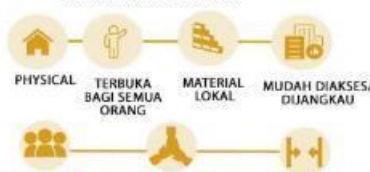

BERSOSIALLSASI GOTONG ROYONG
DAN BEKEHUA KERAS KEBLASAMN BERKMMPUI
DI JALAN SEMPIT

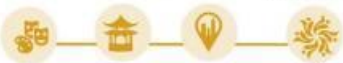

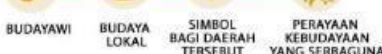

KOSMOLOGI DALAM BUDAYA TIONGHOA

AJARAN KONFUSIANISME

COURTYARD DAPat MEMaENTUK SUATU
DUNIA KECLI" SEGAGAI RUANG

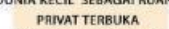
DAN SEALLAN DENGAN PRINSIP FENGSHUI DUDUK-DUDUK SAMA

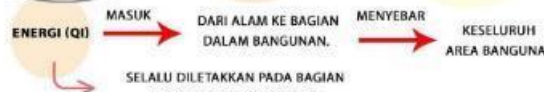
SELALU DILETAKKAN PADA BAGIAN
TENGAH BANGUNAN PADA
SUMBU MEBUJUR (IIN) UTAMA.

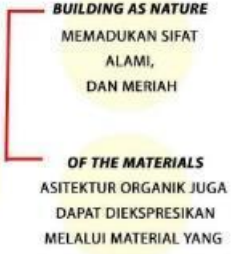

PERSOALAN TAMPILAN BANGUNAN

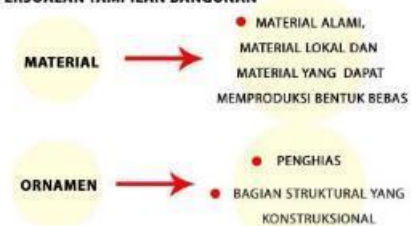

Gambar 7. Konsep Perancangan

Sumber: Penulis, 2020 
Konsep yang digunakan adalah Neo-Vernakular berupa adaptasi dari arsitektur tradisional Tionghoa - Hakka (karena merupakan nenek moyang sebagian besar masyarakat Tionghoa di Jakarta-Kota) dengan konsep eksterior tradisional (mengikuti arsitektur rumah Tulou dari masyarakat Tionghoa - Hakka.) Desain pintu gerbang entrance mengikuti bentuk asli dari pintu gerbang rumah Tulou, terdapat tiga pintu gerbang, yaitu pintu gerbang utama berada pada sisi timur, pintu gerbang selatan, sebagai pintu untuk loading dock/service dan pintu gerbang barat sebagai entrance pengunjung ke dua serta bagian interior ruangan bernuansa modern yang dilengkapi oleh ornamen-ornamen dan warna berciri khas Tionghoa. Desain bangunan tersebut, menggunakan bahan material bangunan earth building yaitu material bangunan alami, material lokal dan material yang dapat memproduksi bentuk bebas serta warna yang merupakan ciri khas Tionghoa (merah, hitam, coklat, cream, kuning, hijau). Terdapat pula courtyard sebagai sumbu membujur (jin) utama dari bangunan.

\section{Struktur Bangunan dan Utilitas}

Struktur utama menggunakan bearing wall karena menghindari perletakan dinding yang tidak sinkron dengan tiang, selain itu, struktur bearing wall tersebut selaras dengan bentuk lingkaran. Dimana beban dari atap langsung menuju ke dinding lalu menuju ke pondasi dan kemudian menuju ke tanah. Penutup atap menggunakan bahan material bangunan atap tanah liat bakar, dengan rangka atap kuda-kuda kayu berciri khas Tionghoa. Bagian kanopi ruang bagian dalam menggunakan kanopi kaca dan pergola sebagai pelindung dari hujan, agar ruangan tetap terang walaupun turun hujan. Sedangkan pada bagian dinding eksterior menggunakan dinding berciri khas Tionghoa yaitu batu bata expose (bata gravel dan bata merah). Pada bagian interior, menggunakan bata merah dengan cat dinding berwarna kuning dan hijau yang dipercaya masyarakat Tionghoa sebagai simbol kekuatan dan kehidupan yang damai dalam fengshui Tionghoa. Terdapat pula storefront kaca sebagai pengganti dinding, second skin rooster gravel berornamen Tionghoa, serta bambu sebagai penyekat ruangan. Pada lantai interior, menggunakan bahan material kayu dan keramik, pada eksterior menggunakan paving block dan aspal serta pada bagian plaza, lantai menggunakan beton.

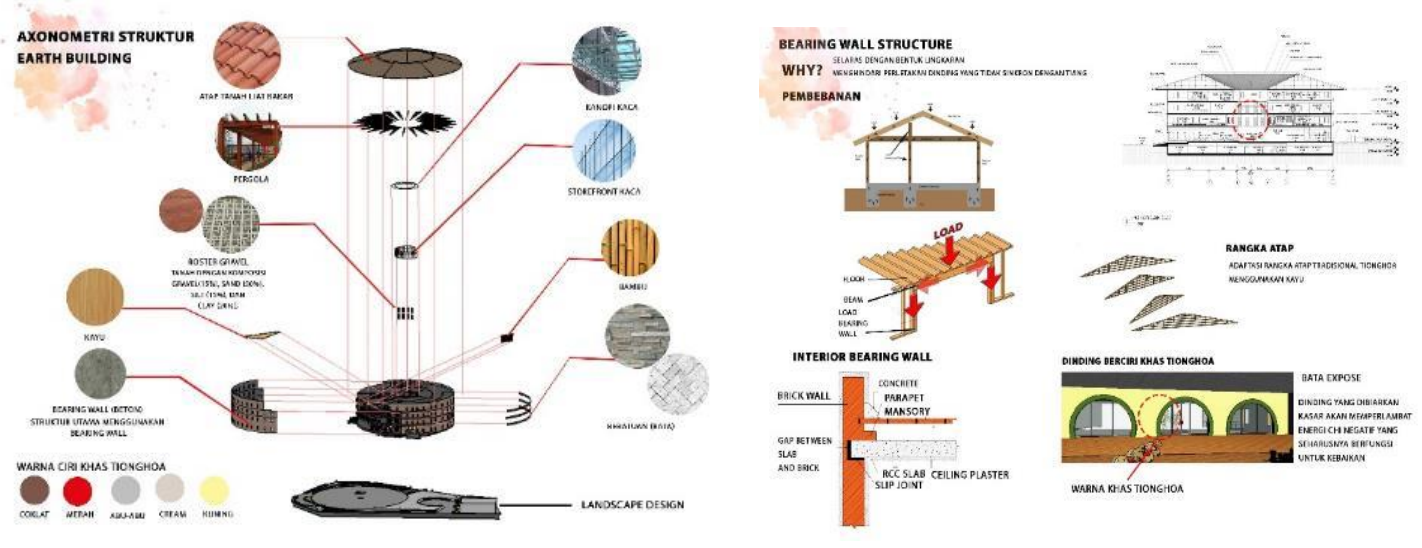

Gambar 8. Skema Struktur

Sumber: Penulis, 2020 


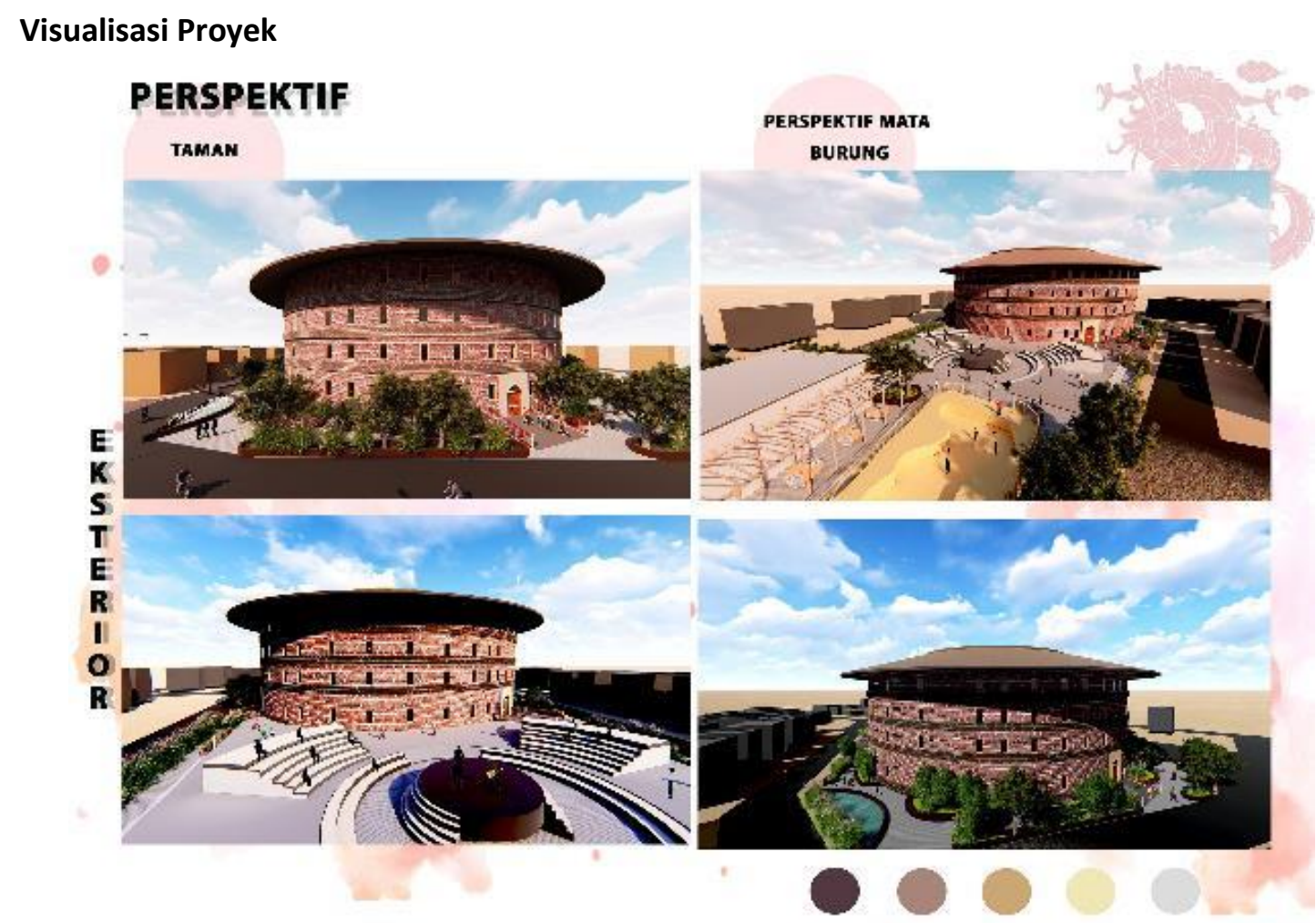

Gambar 9. Gambar Perspektif Eksterior Sumber: Penulis, 2020

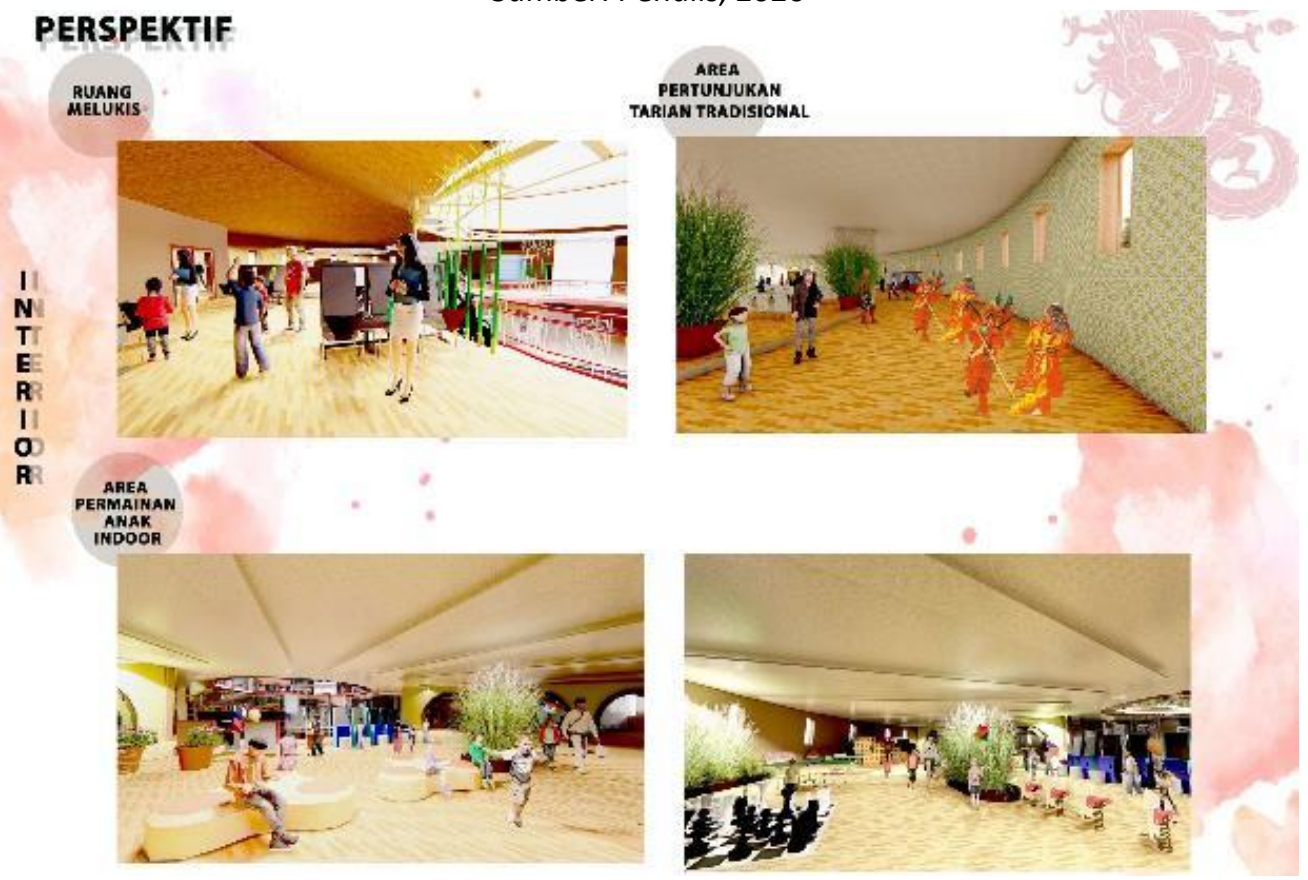

Gambar 10. Gambar Perspektif Interior

Sumber: Penulis, 2020

\section{KESIMPULAN DAN SARAN Kesimpulan}

Dari data dan program yang penulis buat, dapat disimpulkan bahwa setiap program memiliki karakter dengan ciri khas tersendiri dari masing-masing fungsi. Serta perbaikan vitalitas kawasan Glodok tersebut dapat dari aspek lahan, hierarki jalan, tatanan, bentuk dan massa bangunan serta ruang terbuka. Hal ini bertujuan untuk menyajikan potensi kawasan Glodok 
kepada para turis, serta memberikan kesempatan kepada para turis untuk merasakan serta menyalurkan kreatifitasnya secara langsung sebagai bagian dari pelestarian budaya Tionghoa. Informasi yang disajikan melalui media tari teater, musik, foto, cenderamata, dan makanan khas dari beberapa daerah yang ada di Indonesia.

\section{Saran}

Tujuan penyusunan laporan perancangan ini adalah untuk mewadahi masyarakat agar dapat menyalurkan imajinasi ataupun ide kreatif lainnya yang dapat menjadikan kawasannya menjadi kawasan yang kreatif dan inovatif sekaligus dapat melestarikan budaya setempat. Oleh karena itu, penulis mengharapkan adanya saran dan kritik yang bersifat membangun dari berbagai pihak. Mohon maaf apabila terdapat kesalahan kata dalam penyusunan laporan perancangan ini.

\section{REFERENSI}

Carr, S., Mark, F.. Rivlin, L., Stone, A. (1992). Environment and Behavior Series. Public Space. Cambridge University Press.

Hakin, R.(1993). Unsur Perancangan dalam Arsitektur Lansekap. Jakarta: Bumi Aksara.

Kambali, A. (2011). Menelusuri Jejak Tionghoa di Jakarta. Diakses 20 Maret 2020 pukul 17.00 dari www.sejarah.kompasiana.com

Koentjaraningrat. (1992). Kebudayaan, Mentalitas dan Pembangunan. Jakarta: PT Gramedia.

Purnasari, M. (2015). Revitalisasi Kawasan Glodok Pancoran sebagai Kawasan Wisata Budaya di Jakarta Barat. Binus University.

Sinar Harapan (2014). Jalan Pancoran Glodok dari Masa ke Masa: Menjadi pusat ekonomi pada tahun 1872. Diakses 20 Maret 2020 pukul 20.30 dari http://sinarharapan.co/news/read/140407033/Jalan-Pancoran-Glodok-dari-Masa-keMasa-span span

Suroso, L. (2007). Jakarta China Town: Jejak Sejarah Tionghoa di Jakarta. Diakses 20 Maret 2020 pukul 20.20 dari https://lisasuroso.wordpress.com/2007/07/04/jakarta-china-townjejak-sejarah-tionghoa-di-jakarta/

Vestheim, G. (2012). Cultural policy-making: negotiations in an overlapping zone between culture, politics and money, International Journal of Cultural Policy.18(5), pp. 530-544.

Zahnd, M. (1999). Perancangan Kota Terpadu, Teori Perancangan Kota dan Penerapannya. Yogyakarta: Kanisius. 